\title{
Efficiency Evaluation of Green Technology Innovation of China's Industrial Enterprises Based on SBM Model and EBM Model
}

\author{
Wei Chen $\left(\mathbb{D},{ }^{1}\right.$ Liying Pan $\left(\mathbb{D},{ }^{1}\right.$ Chaoran Lin $(D),{ }^{1,2}$ Mengqi Zhao $\left(\mathbb{D},{ }^{3}\right.$ Tan Li $(D)$, \\ and Xuan Wei $\mathbb{D}^{4}$ \\ ${ }^{1}$ School of Economics and Management, Harbin Engineering University, Harbin 150001, China \\ ${ }^{2}$ College of Computer Science and Technology, Harbin Engineering University, Harbin 150001, China \\ ${ }^{3}$ Jingdong Digits Technology Holding Co., Ltd., Beijing 100176, China \\ ${ }^{4}$ School of Mathematic and Quantitative Economics, Shandong University of Finance and Economics, Jinan 250014, China
}

Correspondence should be addressed to Chaoran Lin; hcab@qq.com

Received 3 October 2020; Revised 25 February 2021; Accepted 24 April 2021; Published 7 May 2021

Academic Editor: Gordon Huang

Copyright (c) 2021 Wei Chen et al. This is an open access article distributed under the Creative Commons Attribution License, which permits unrestricted use, distribution, and reproduction in any medium, provided the original work is properly cited.

\begin{abstract}
The industrial revolution has brought a leap in productivity; however, some severe ecological environment and resource problems are coming out with the development of industrialization. To achieve sustainable development of social economy, green technology innovation emerges in response to the proper time and conditions. In this context, the correct approach to measure the efficiency of green technology innovation in China's industrial enterprises is an important research topic. Based on existing studies, this paper divides innovation activities into two stages based on the innovation value chain and constructs a two-stage evaluation index system including all kinds of undesirable outputs transferred from negative externalities of the ecological environment. To evaluate green technology innovation efficiency, SBM and EBM network DEA models are applied to conduct empirical analysis from the perspective of time and space. This paper also calculates the efficiency values based on the SBM model and the EBM model, respectively, and compares the differences between them. The results show that the efficiency value of the achievement transformation stage is significantly higher than that of technology development stage; there are noticeable gaps in the efficiency of green technology innovation between different regions of China. Besides, the eastern region has a better performance in green technology innovation than the western region and Qinghai has the best green technology innovation performance. Combining the empirical results, the corresponding policy recommendations are put forward.
\end{abstract}

\section{Introduction}

The industrial revolution has brought a leap in productivity; however, some severe ecological environment and resource problems are coming out with the industrialization development. According to WWF statistics, the renewal rate of natural resources lags behind that of natural resources depletion with human activities about $20 \%$. As a result, the biodiversity on the Earth has been reduced by $35 \%$, and $20 \%$ of the Earth's land is seriously threatened by drought and desertification in the last decade. Facing the problems above, the United Nations issues several agreements, such as "United Nations Framework Convention on Climate Change," "Kyoto Protocol," and "Paris Agreement," to set target ranges for countries all over the world to deal with global warming. In China, industrialization has made a great contribution to economic development with its rapid development; however, there are also many environmental problems. According to the China Environment Bulletin in 2018, the air quality indexes of 217 cities are out of limits, and the water quality of the coastal area with better economic development is poor by and large. Considering "Five in one" strategic layout, the Chinese government actively promotes the ecological and civilization construction in the 19th National Congress of the Communist Party of China.

When environmental pollution and resource depletion become serious social problems, technology is increasingly regarded as the primary cause of pollution and environmental destruction. Only when technological innovation and environmental protection are closely integrated, the 
implementation of green technological innovation is the fundamental way to achieve sustainable development of social economy. Green technological innovation refers to a type of technology that is considered environmentally friendly based on its production process or its supply chain. In this connection, the concept of green technology innovation is put forward in academic and aroused the wide attention of scholars in the last decade [1]. Green technology innovation, also called ecological technology innovation, is one kind of technology innovation. It emphasizes not only economic benefits but also environmental and ecological benefits and requires technology innovation not only to save resources and energy but also to avoid, eliminate, or mitigate the pollution and destruction of the natural environment. At the national level, the essence of green technology innovation is to implement the national policy of environmental protection, eliminate backward production capacity, promote industrial transformation and upgrading, and realize sustainable economic development. In other words, green technology innovation not only stands for energy conservation and emission reduction in answer to the government's call but also means the improvement for enterprise's innovation and competitiveness. Therefore, the efficiency of green technology innovation of China's enterprises, especially industrial enterprises, is a great problem that needs to be focused on.

Taking China's industrial enterprises as the research object, this study (1) divides the innovation into two stages and evaluates the efficiency of green technology innovation; (2) measures the green technology innovation efficiency of China and its different regions; (3) analyzes the key factors of either growth or decline of green technology innovation efficiency and finds out the deficiencies in green technology innovation of China's industrial enterprises; and (4) puts forward the scientific way to improve the efficiency of green technology innovation of China's industrial enterprises. On the basis of empirical results and in combination with China's national conditions, suggestions of this study contribute to the international competitiveness enhancement of China's industrial enterprises and sustainable economic development in China.

\section{Literature Review}

In recent years, many scholars have further investigated their research on green innovation efficiency, and their perspectives and methods have been gradually multiplex. Based on existing studies, the nonparametric method is commonly used to measure the efficiency of green innovation, especially the data envelopment analysis (DEA) and its various extended models, which are good at dealing with multiple input and output indicators. Luo and Liang [2] and Qian et al. [3] regarded environmental load as undesirable output and measured the efficiency of regional green innovation in China using various extended DEA models. In their analysis, they all find a significant regional difference of "high in the east and low in the west" in terms of China's green innovation efficiency. Besides, many studies focus on the convergence of innovation efficiency or innovation ability. For example, Szajt [4] investigated the evolution trend of OECD countries' innovation level based on the $\beta$-convergence and spatiotemporal model; Bai et al. [5] and Li and Long [6] analyzed the knowledge base of green technology in China based on mapping knowledge domains; Pan and Liu [7] and Li and Zhu [8] analyzed the convergence of innovation efficiency of industrial enterprises and large- and medium-sized enterprises in China, respectively; Zhang et al. [9] assessed the corporate green technology progress and environmental governance performance based on the panel data on industrial enterprises above designated size in Anhui Province, China.

Technology innovation efficiency refers to the technical efficiency of innovation activities. Several studies have investigated the Efficiency Stage Theory, which reveals the internal laws of innovation. For example, Furman et al. [10] considered that innovation follows the chain structure with links linked to each other, and it can be divided into two stages: R\&D innovation and achievement transformation. The main body of the first stage is colleges and universities and focuses on the innovation of basic science; the second stage is the transformation and output process of scientific and technological achievements led by the chairman or the person in charge of the enterprise. Based on R\&D innovation in the first stage, the basic science is applied to form practical technologies of enterprises in the second stage. Similarly, Hansen and Birkinshaw [11] provided a framework, the innovation value chain, to evaluate innovation performance. In their study, the innovation includes three main stages: idea generation, transformation, and dissemination. In the same vein, Liu et al. [12] established an improved SBM-DEA model to analyze regional innovation efficiency considering environmental pollution and innovation failure and predicted the green technology innovation efficiency of China's major industrial regions in the future via four cluster index systems. Fang et al. [13] constructed a model to evaluate the efficiency of green industry innovation activities by nonracial directional distance function and data envelopment analysis. On this basis, this study discusses the damage of heavy pollution industry and the efficiency of green technology innovation. Tang et al. [14] took the evidence from China's industrial enterprises to study the effectiveness of command-and-control regulation on green innovation performance.

With the development and application of relational network DEA model, a number of studies begin to associate technological innovation with environmental protection and calculate the estimated value of green technological innovation through network DEA. Xiao et al. [15] decomposed the environmental index into six relative indicators: industrial waste gas emission, wastewater discharge, solid waste production, sulfur dioxide emission, dust emission and smoke, and dust emission and considered these indicators during the evaluation of achievement transformation stage. Based on the enterprise innovation value chain, Bai et al. [16] improved the calculation framework by considering expected profit during evaluating technological innovation for non-iron and steel enterprises. On this basis, they calculated the green technology innovation efficiency and green total factor productivity of 12 Chinese iron and steel enterprises from 2011 to 2017. In a follow-up study, Xu et al. [17] employed the carbon emission model, super DEA model, and PVAR model to measure green innovation 
efficiency of the equipment manufacturing industry. Fan et al. [18] considered the heterogeneity of environmental regulation, and this study calculated the green innovation efficiency of 235 cities in Mainland China from 2004 to 2016. Wang et al. [19] explored the impacts of the changing urban form on the ecological efficiency of administrative areas and urban agglomerations in China under different regional scales using the slack-based measure of the efficiency model.

Existing studies about technology innovation efficiency mainly measure industrial technology innovation efficiency from the perspective of the independent innovation input. Based on the research of technological innovation, green technology innovation is studied specifically in different stages and environmental indicators are included in the technological innovation evaluation system as undesirable output, which endows the technological innovation with rich connotation. At the same time, more and more studies employ the SBM model, which is more suitable to consider the undesirable output in the evaluation index system and deal with the slack variable problem compared with the traditional DEA model. However, the purpose of calculating the efficiency value by the SBM model is to optimize the efficiency, which may not find the shortest path to reach the efficiency frontier, and there may be no solution. As a result, to make up for the shortcomings of the existing research, this paper extends the efficiency evaluation of green technology innovation of industrial enterprises from the following aspects. On the one hand, this paper divides the innovation activities into two stages: technology development and achievement transformation, and the essence of achievement transformation stage is industrialization. On this basis, environmental indicators are taken into account in the second stage as undesirable outputs during evaluation. To make results more convincing, this paper employs the SBM network DEA model and EBM network DEA model to conduct a comprehensive evaluation and analyzes the green innovation efficiency from the perspective of time and space based on SBM efficiency value and EBM efficiency value.

\section{Model and Algorithm}

3.1. SBM Model. Data envelopment analysis (hereafter DEA) models can be used to assess the efficiency of multiple inputs and outputs. Commonly, there are two main kinds of DEA models: models based on radial measures and models based on nonradial measures, and the SBM model belongs to the latter. Radial measurements do not consider the slack variables (input is excessive, and output is insufficient) and assume that all elements change proportionally, which often deviates from reality. In this study, to find the optimal solution to reach the efficiency frontier, we construct a nonradial and nonangle SBM model, which could fully consider the slack of input and output. Correspondingly, the constraints of the linear programming of the model are further changed. Suppose there are a set number of decision-making units (hereafter DMU) in a system and each DMU has three vectors: input $x$, desirable output $y^{g}$, and undesirable output $z^{b}$. The SMB model can be expressed as follows:

$$
\begin{aligned}
& \operatorname{Min} \rho=\frac{1-1 / m \sum_{i=1}^{m}\left(s_{i}^{-} / x_{i k}\right)}{1+\left(1 / s_{1}+s_{2}\right)\left(\sum_{r=1}^{s_{1}}\left(e_{r}^{g} / y_{r k}^{g}\right)+\sum_{r=1}^{s_{2}}\left(e_{r}^{b} / z_{r k}^{b}\right)\right)}, \\
& \text { s.t. }\left\{\begin{array}{l}
X \lambda+s_{i}^{-}=x_{k} \\
Y^{g} \lambda-s_{i}^{g}=y_{k}^{g} \\
Z^{b} \lambda+s_{r}^{b}=z_{k}^{b} \\
\lambda, s_{i}^{-}, s_{i}^{g}, s_{r}^{b} \geq 0
\end{array}\right.
\end{aligned}
$$

In formula (1), $s_{i}^{-}, s_{i}^{g}$, and $s_{r}^{b}$ indicate the slack of input, desirable output, and undesirable output, respectively, $\lambda$ is a weight vector, and $\rho$ is the objective function.

3.2. EBM Model. Nonradial SBM models are based on slack variable efficiencies and avoid radial estimation assumptions and seek to maximize the input and output inefficiencies by identifying the points farthest from the frontier, which means that the original ratio information for the efficiency front projection value is lost. Therefore, the improvement distance is excessively large, and the results are often inconsistent with expectations. In view of the shortcomings of the SBM model, we construct the EBM model to relax the assumptions and change the radial expectation function of synchronous change between time input and cost elements. The EBM model is defined as follows:

$$
\operatorname{Min} \rho=\frac{\theta-\varepsilon_{x}\left(1 / \sum_{i=1}^{m} \omega_{i}^{-}\right) \sum_{\mathbf{i}=1}^{m} x_{i k}\left(\omega_{i}^{-} s_{i}^{-} / x_{i k}\right)}{\phi+\varepsilon_{y}\left(1 / \sum_{i=1}^{q} \omega_{r}^{g}\right) \sum_{\mathbf{r}=1}^{q}\left(\omega_{r}^{g} s_{r}^{g} / y_{r k}+\varepsilon_{z}\right)\left(1 / \sum_{t=1}^{p} \omega_{i}^{b}\right) \sum_{\mathbf{i}=1}^{p}\left(\omega_{r}^{b} s_{r}^{b} / z_{t k}\right)}\left\{\begin{array}{l}
X \lambda+s_{i}^{-}=\theta x_{k} \\
Y^{g} \lambda-s_{i}^{g}=\varphi y_{k}^{g} \\
Z^{b} \lambda+s_{r}^{b}=\varphi z_{k}^{b} \\
\lambda, s_{i}^{-}, s_{i}^{g}, s_{r}^{b} \geq 0
\end{array} .\right.
$$

In formula (2), the mathematical symbols are basically the same as that in formula (1). In addition, $\varepsilon_{x}$ is a combination of the radial and nonradial key parameters, the value range for which is $(0,1)$. 
3.3. Network DEA. The traditional DEA model is a "black box," where inputs are transformed into outputs. The actual transformation process is generally not modeled explicitly; rather, one simply species what enters the box and what exits. Nevertheless, when the traditional DEA model is applied to analyze Chinese industrial enterprises, it cannot reveal its complex characteristics and cannot deeply measure the efficiency of green technology innovation. In comparison, the network DEA, which is the improvement of the traditional DEA model, can deeply reveal the internal mechanism of green technology innovation. The network DEA is not a simple repeat of the traditional DEA model and allows the efficiency value measured progressively according to the chain structure. Therefore, the network DEA model better suits this study from the perspective of the innovation value chain.

Assume that there are $n$ DMUs and each DMU has two nodes and one intermediate variable. Specifically, $k \in(1,2)$ denotes the node 1 and node $2 ; x_{i j}^{k}$ denotes the inputs; $m_{k}$ denotes the number of input indicators in each node; $x_{j}^{k}=$ $\left(x_{1, j}^{k}, \ldots, x_{i, j}^{k}\right)^{T} \in R^{m k}+\left(1 \leq P_{k} \leq m_{k}\right)$ denotes the vector of (exogenous) inputs that is allocated to node $k ; y^{2} \in R_{+}^{12}$ denotes the final outputs; $z^{2} \in R_{+}^{12}$ denotes the intermediate output produced by node 1 and delivered to node 2 as input; and $\lambda_{j}^{k}$ denotes the intensity of node $k$. Then, the DMU production set can be expressed as the following formula:

$$
\left\{\begin{array}{l}
x^{k} \geq \sum_{j=1}^{n} x_{j}^{k} \lambda_{j}^{k}(k=1,2) \\
y^{2} \leq \sum_{j=1}^{n} y_{j}^{2} \lambda_{j}^{2} \\
z^{12}=\sum_{j=1}^{n} z_{j}^{12} \lambda_{j}^{1} \\
z^{12}=\sum_{j=1}^{n} z_{j}^{12} \lambda_{j}^{2} \\
\sum_{j=1}^{n} \lambda_{j}^{k}=1(\forall k, j)
\end{array} .\right.
$$

On the basis of the production possibility set in formula (3), we evaluate $\mathrm{DMU}_{0}(1 \leq o \leq n)$ and construct an input oriented linear programming model as follows:

$$
\begin{gathered}
\theta_{0}^{*}=\min _{1 \leq o \leq n} \sum_{k=1}^{2} w^{k}\left[1-\frac{1}{e_{k}}\left(\sum_{i=1}^{m_{k}} \frac{e_{i 0}^{k-}}{x_{i 0}}\right)\right], \\
\text { s.t. }\left\{\begin{array}{l}
x_{0}^{k}=x^{k} \lambda^{k}=s_{0}^{k-}(k=1,2) \\
y_{0}^{2}=Y^{2} \lambda^{2}-s_{0}^{2+} \\
Z^{12} \lambda^{1}=Z^{12} \lambda^{12} \\
\sum_{j=1}^{n} \lambda_{j}^{k}=1(k=1,2), \quad \lambda_{j}^{k} \geq 0(\forall j, k) . \\
\sum_{k=1}^{2} w^{k}=(\forall k), \quad w^{k} \geq 0(\forall j, k)
\end{array}\right.
\end{gathered}
$$

In formula (4), $w^{k}$ is the weight of node $k$ and $e_{0}^{k-}$ and $e_{0}^{k+}$ denote the slack variables adjusted by inputs and outputs, respectively. The total efficiency is the weighted average value of two-stage efficiencies.

\section{Data and Indicators}

This paper selects statistical data to evaluate the green innovation efficiency of industrial enterprises in China. Relevant data are from China High Tech Statistical Yearbook, China Statistical Yearbook, and China Science and Technology Statistical Yearbook from 2008 to 2017. It should be noted that the data of Tibet Autonomous Region are excluded mainly because of the data missing of some key indicators.

In this paper, the technology innovation of China's industrial enterprises is divided into two stages: technology development and achievement transformation. Because the characteristic of the two stages is not the same, the emphasis of indicator selection in the two stages is also different. The first stage focuses on the technological innovation activities of industrial enterprises, and the selected input and output indicators are closely related to technological innovation, while the second stage focuses on industrialization ability, that is, the ability to transform technology innovation into enterprise profits. Considering the inherent characteristics of achievement transformation, the indicators are divided into desirable output and undesirable output. Based on the innovation value chain, the output of the first stage is taken as the input in the second stage.

4.1. Indicators in Technology Development Stage. In terms of technology development stage, "the full-time R\&D personnel equivalent" and "R\&D funds" are selected as input indicators, corresponding to the human and financial input, respectively; "the number of valid invention patents" and "the number of patent applications" are the output indicators in the first stage and represent the research results of technology development activities. The selection of these indicators was mainly based on relevant literature $[12,13,16-18]$. These indicators are listed in Table 1.

4.2. Indicators in Achievement Transformation Stage. Based on the innovation value chain, the outputs in the first stage are the inputs in the second stage. In addition, "expenditure on introduction, purchase, assimilation, and upgrading of technology" is added as the input indicators in the second stage. Referring to the study by Xiao et al. [15], "sales revenue of new products" and "gross industrial production" are selected as the desirable output indicators; "wastewater discharge," "smoke and dust emission," and "industrial solid waste production" are selected as the undesirable output indicators. These indicators are listed in Table 2.

\section{Empirical Analysis}

5.1. Green Technology Innovation Efficiency Evaluation Based on SBM Model. According to the two-stage SBM model 
TABLE 1: Input and output indicators in technology development stage.

\begin{tabular}{|c|c|}
\hline Category & Indicator \\
\hline Inputs & $\begin{array}{l}\text { The full-time R\&D personnel equivalent } \\
\text { R\&D funds }\end{array}$ \\
\hline Outputs & $\begin{array}{l}\text { The number of valid invention patents } \\
\text { The number of patent applications }\end{array}$ \\
\hline
\end{tabular}

TABLE 2: Input and output indicators in achievement transformation stage.

\begin{tabular}{lc}
\hline Category & Indicator \\
\hline Inputs & $\begin{array}{c}\text { The number of valid invention patents } \\
\text { The number of patent applications } \\
\text { Expenditure on introduction, purchase, } \\
\text { assimilation, and upgrading of technology }\end{array}$ \\
\hline Desirable outputs & $\begin{array}{c}\text { Sales revenue of new products } \\
\text { Gross industrial production }\end{array}$ \\
\hline Undesirable & $\begin{array}{c}\text { Wastewater discharge } \\
\text { outputs }\end{array}$ \\
\hline
\end{tabular}

based on the chain network, the green technology innovation efficiency of China's industrial enterprises is calculated via MaxDEA 6.6 Pro.

5.1.1. Temporal Analysis. As shown in Figure 1, from 2008 to 2017, the green technology innovation efficiency of China's industrial enterprises shows a general upward trend, and both the efficiency of technology development stage and achievement transformation stage increase in twists and turns. Comparatively speaking, the innovation efficiency of technology development stage is far lower than that of achievement transformation stage. Since 2011, the total efficiency is maintained between 0.7 and 0.8 . The growth of achievement transformation efficiency promotes the increase in the total efficiency of green technology innovation, whereas technology development efficiency does not contribute.

In terms of technology development stage, the average efficiency value from 2008 to 2017 is 0.564 . The performance of technology development is basically stable, and the efficiency value increases slightly. From 2008 to 2009, the technology development efficiency dropped sharply and reached the minimum in 2009. From 2010 to 2012, the efficiency of technology development increased slowly. Since 2013, the value of technology development efficiency stays stable at about 0.6. In terms of achievement transformation stage, the average of efficiency value from 2008 to 2017 is 0.832 . From 2008 to 2015, the efficiency value maintains growth with an increase from 0.731 to 1.001 . Since then, it has experienced two slight drops. In detail, it dropped from 0.730 to 0.688 in 2009 and dropped from 0.923 to 0.878 in 2014. From 2015 to 2017, the achievement transformation efficiency shows a significant downward trend and the efficiency value drops to 0.868 in 2017 . Due to the specificity of green innovation, the difficulty of its technology development lies in the foresight of the economics of its results.

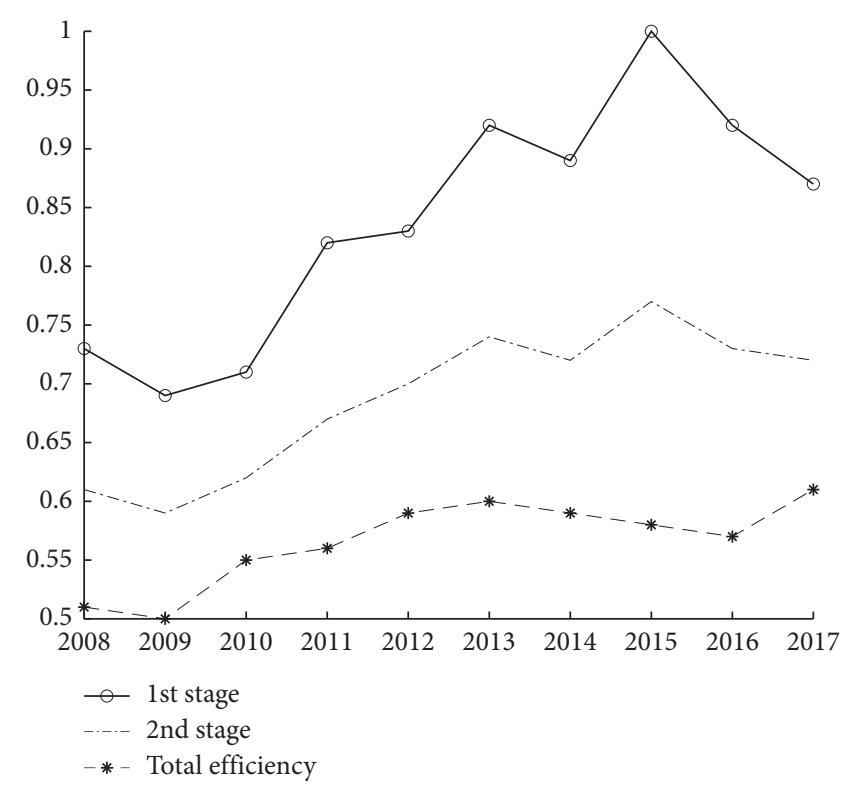

FIgURE 1: Temporal analysis for green technology innovation efficiency of China's industrial enterprises (SBM model).

Therefore, when the technology ontology is obtained through technology $\mathrm{R} \& \mathrm{D}$, it often faces the challenge of transforming the results into economic benefits.

5.1.2. Spatial Analysis. The spatial analysis results for green innovation efficiency of China's industrial enterprises based on the SBM model are shown in Table 3.

According to the evaluation results based on the SBM model in Table 3, it can be seen that the eastern region has a better performance in green technology innovation (with the total efficiency value of 0.891 ) than the western region (with the total efficiency value of 0.709 ) and the central region (with the total efficiency value of 0.671 ). Specifically, in the eastern region, the efficiency value in technology development stage and achievement transformation stage is 0.718 and 0.891 , respectively; in the western region, the efficiency value in technology development stage and achievement transformation stage is 0.512 and 0.695 , respectively; in the central region, the efficiency value in technology development stage and achievement transformation stage is 0.697 and 0.671 , respectively. Besides, this paper uses a superefficient DEA algorithm that allows DMUs arriving at the efficiency frontier surface to obtain more differentiated efficiency values, resulting in some DMUs with efficiency values exceeding 1 . Overall, there are significant differences both in technology development stage and achievement transformation stage, and the efficiency value of achievement transformation is obviously higher than that of technology development.

All the provinces with the total efficiency value over 1 are located in the eastern region, including Hainan, Guangdong, and Beijing. The results show that the high-level green technology innovation in Hainan is mainly caused by the better performance in achievement transformation stage. The efficiency value in technology development stage of 
TABLE 3: Spatial analysis for green innovation efficiency of China's industrial enterprises (SBM model).

\begin{tabular}{|c|c|c|c|c|}
\hline Region & DMU (province) & The first stage efficiency & The second stage efficiency & Total efficiency \\
\hline \multirow{12}{*}{ Eastern region } & Hainan & 0.927 & 5.550 & 2.268 \\
\hline & Guangdong & 2.613 & 0.693 & 1.345 \\
\hline & Beijing & 1.649 & 0.808 & 1.155 \\
\hline & Zhejiang & 0.687 & 1.321 & 0.953 \\
\hline & Jiangsu & 0.848 & 1.066 & 0.951 \\
\hline & Shanghai & 0.726 & 1.000 & 0.852 \\
\hline & Tianjin & 0.610 & 1.000 & 0.781 \\
\hline & Fujian & 0.437 & 0.979 & 0.654 \\
\hline & Shandong & 0.419 & 1.000 & 0.648 \\
\hline & Hebei & 0.335 & 0.955 & 0.566 \\
\hline & Liaoning & 0.414 & 0.743 & 0.555 \\
\hline & Eastern region & 0.718 & 1.106 & - \\
\hline \multirow{9}{*}{ Central region } & Jilin & 0.343 & 1.149 & 0.628 \\
\hline & Jinan & 0.378 & 1.039 & 0.627 \\
\hline & Hubei & 0.472 & 0.791 & 0.611 \\
\hline & Hunan & 0.657 & 0.553 & 0.603 \\
\hline & Anhui & 0.853 & 0.380 & 0.570 \\
\hline & Jiangxi & 0.329 & 0.788 & 0.509 \\
\hline & Heilongjiang & 0.338 & 0.747 & 0.502 \\
\hline & Shanxi & 0.328 & 0.476 & 0.395 \\
\hline & Central region & 0.434 & 0.697 & - \\
\hline \multirow{12}{*}{ Western region } & Qinghai & 0.415 & 2.119 & 0.938 \\
\hline & Xinjiang & 0.624 & 0.963 & 0.775 \\
\hline & Chongqing & 0.599 & 0.773 & 0.681 \\
\hline & Sichuan & 0.721 & 0.553 & 0.631 \\
\hline & Ningxia & 0.539 & 0.673 & 0.603 \\
\hline & Shaanxi & 0.460 & 0.688 & 0.562 \\
\hline & Yunnan & 0.630 & 0.471 & 0.545 \\
\hline & Guangxi & 0.472 & 0.620 & 0.541 \\
\hline & Inner Mongolia & 0.238 & 1.201 & 0.534 \\
\hline & Guizhou & 0.793 & 0.279 & 0.470 \\
\hline & Gansu & 0.406 & 0.465 & 0.434 \\
\hline & Western region & 0.512 & 0.695 & - \\
\hline
\end{tabular}

Guangdong and Beijing is 2.613 and 1.649, respectively. In addition, there are three provinces whose total efficiency value is lower than 0.5 , all of which are located in the central and western regions, namely, Shanxi, Guizhou, and Gansu, with the total efficiency value of $0.395,0.470$, and 0.434 , respectively.

\subsection{Green Technology Innovation Efficiency Evaluation Based on EBM Model}

5.2.1. Temporal Analysis. As shown in Figure 2, from 2008 to 2017, the green technology innovation efficiency of China's industrial enterprises has fluctuated smoothly, with an average of 0.729 in the past ten years. The efficiency of technology development has been climbing from 2008 to 2013 and continuously declines after reaching the maximum of 0.640; the efficiency of achievement transformation also rises in the twists and turns. Comparatively, the efficiency value in technology development stage is 0.564 , which is lower than 0.832 in achievement transformation stage.

In terms of technology development stage, the average of efficiency value from 2008 to 2017 is 0.533 and its dynamic change can be roughly divided into two stages. The technology development efficiency increases slowly from 2008 to 2013, and its statistic value decreases to 0.524 after reaching the maximum of 0.640 . In terms of achievement transformation stage, the average efficiency value from 2008 to 2017 is 0.925 . The efficiency value of achievement transformation increases from 0.860 to 0.978 from 2008 to 2012 and then fluctuates in the range of 0.9 to 1.0.

5.2.2. Spatial Analysis. The spatial analysis results for green innovation efficiency of China's industrial enterprises based on the EBM model are shown in Table 4.

According to the evaluation results based on the EBM model in Table 4, it can be seen that the eastern region has a better performance in green technology innovation (with the total efficiency value of 0.861 ) than the western region (with the total efficiency value of 0.643 ) and the central region (with the total efficiency value of 0.577 ). Specifically, in the eastern region, the efficiency value in technology development stage and achievement transformation stage is 0.690 and 1.074, respectively; in the western region, the efficiency value in technology development stage and achievement transformation stage is 0.498 and 0.831 , respectively; in the central region, the efficiency value of technology 


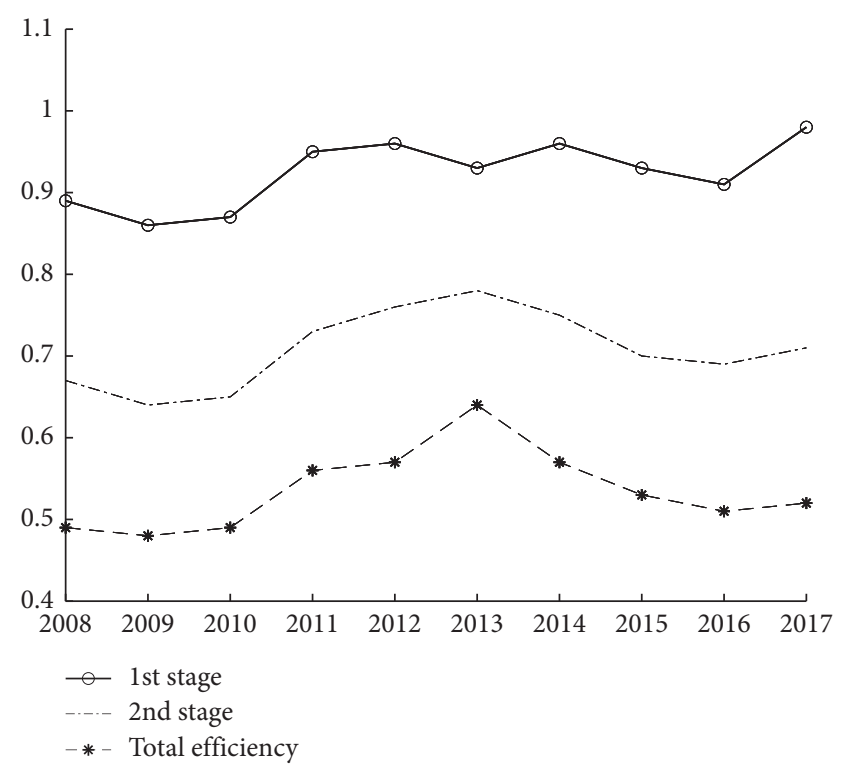

FIGURE 2: Temporal analysis for green technology innovation efficiency of China's industrial enterprises (EBM model).

development and achievement transformation is 0.396 and 0.841, respectively. Consistent with the evaluation results based on the SBM model, there are significant differences both in technology development stage and achievement transformation stage between different regions and the efficiency value of achievement transformation is generally higher than that of technology development.

Most of the provinces with the total efficiency value more than 1, such as Guangdong, Beijing, Zhejiang, and Hainan, are located in the eastern region. The efficiency value of technology development stage of Guangdong, Beijing, and Zhejiang is $1.791,1.323$, and 1.128 , respectively, which are higher than that of Hainan. Notably, what is inconsistent with the SBM model evaluation results only focus on the Qinghai Province. Results based on the EBM model algorithm show that Qinghai has the best green technology innovation performance and the total efficiency value, and the efficiency value of technology development stage and achievement transformation stage is $1.316,1.156$, and 1.499, respectively. In addition, there are three provinces whose total efficiency values are lower than 0.5 , all of which are located in the central and western regions. The total efficiency value of these provinces, namely, Shanxi, Guizhou, and Gansu is 0.391, 0.467, and 0.464, respectively.

\subsection{Comparative Analysis of Evaluation Results of SBM Model} and EBM Model. The comparative analysis results of the SBM model and EBM model are shown both in Table 5 and Figure 3.

It can be seen from Figure 3 that the green technology innovation efficiency shows a general upward trend both in SBM model evaluation and EBM model evaluation which indicates that China's industrial enterprises have paid more and more attention to the technology development and have the capacity to transform technology achievements into profit. The efficiency value of achievement transformation stage is obviously higher than that of the technology development stage.

As shown in Figure 3, both the inputs and the outputs in the technology development stage are growing rapidly; however, the growth rate of the inputs in the first stage is much higher than that of the outputs, which indicates that the efficiency of technology development is relatively low. The reasons accounting for it are reflected mainly in the following two aspects. On the one hand, with the enhancement of technology innovation ability of China's industrial enterprises, the marginal benefit of technology innovation investment is gradually decreasing. On the other hand, "the number of valid invention patents" and "the number of patent applications" are selected as intermediate variables. As a consequence, the contribution of the initial inputs to these intermediate outputs cannot be fully reflected.

In terms of achievement transformation efficiency, there is difference between SBM model evaluation result and EBM model evaluation result. In detail, before 2013, although the efficiency value calculated by the SBM model and the EBM model changed in the same direction, the difference between them is significantly large; after 2013, the efficiency values calculated by the SBM model and the EBM model even change in opposite direction. This inconsistency is mainly due to the algorithm difference between the SBM model and the EBM model. Considering the undesirable outputs during the evaluation, the EBM model can integrate the advantages of different functions, so the efficiency value calculated by the EBM model is more reliable.

In Table 6, it can be seen that there is a noticeable gap in green technology innovation of China's industrial enterprises between different regions. Provinces located in the eastern region perform relatively better, and the green technology innovation efficiency of the central region is slightly higher than that of the western region. The possible explanations might be mainly in the following aspects. Firstly, there are a large number of industrial enterprises with mature sales network and market system in the eastern region. Secondly, coastal geography advantages, such as more convenient transportation and more foreign trade industrial bases, also promote the competitive capacity to transform technology into profits. Thirdly, most of the eastern cities have been carrying out industrial transformation and upgrading vigorously, eliminating backward production capacity, propping up high-tech industries, and developing modern service industry and modern manufacturing industry. Fourthly, the governments in the eastern region transfer enterprises with high pollution, high energy consumption, and high emission to the central and western regions and retain the $\mathrm{R} \& \mathrm{D}$ center, which not only improves the environment of the eastern region but also makes the eastern cities more livable. Overall, these factors provide more highly paid jobs, which are conducive to the talents introduction and further improve the efficiency of green technology innovation in the eastern region.

The green technology innovation efficiency of the central region is relatively low, which is mainly due to the 
TABLE 4: Spatial analysis for green innovation efficiency of China's industrial enterprises (EBM model).

\begin{tabular}{|c|c|c|c|c|}
\hline Region & DMU (province) & The first stage efficiency & The second stage efficiency & Total efficiency \\
\hline \multirow{12}{*}{ Eastern region } & Guangdong & 0.923 & 1.791 & 1.286 \\
\hline & Beijing & 0.881 & 1.323 & 1.080 \\
\hline & Zhejiang & 0.995 & 1.128 & 1.059 \\
\hline & Hainan & 1.000 & 1.000 & 1.000 \\
\hline & Jiangsu & 0.837 & 1.086 & 0.954 \\
\hline & Shanghai & 0.827 & 1.000 & 0.909 \\
\hline & Tianjin & 0.678 & 1.000 & 0.823 \\
\hline & Fujian & 0.546 & 0.961 & 0.724 \\
\hline & Shandong & 0.491 & 1.000 & 0.701 \\
\hline & Liaoning & 0.464 & 0.819 & 0.616 \\
\hline & Hebei & 0.356 & 0.961 & 0.585 \\
\hline & Eastern region & 0.690 & 1.074 & 0.861 \\
\hline \multirow{9}{*}{ Central region } & Jilin & 0.420 & 1.027 & 0.657 \\
\hline & Hunan & 0.525 & 0.819 & 0.656 \\
\hline & Hubei & 0.473 & 0.893 & 0.650 \\
\hline & Henan & 0.408 & 1.000 & 0.639 \\
\hline & Anhui & 0.463 & 0.725 & 0.580 \\
\hline & Jiangxi & 0.367 & 0.847 & 0.557 \\
\hline & Heilongjiang & 0.347 & 0.843 & 0.541 \\
\hline & Shanxi & 0.239 & 0.640 & 0.391 \\
\hline & Central region & 0.396 & 0.841 & 0.577 \\
\hline \multirow{12}{*}{ Western region } & Qinghai & 1.156 & 1.499 & 1.316 \\
\hline & Xinjiang & 0.711 & 0.999 & 0.843 \\
\hline & Chongqing & 0.742 & 0.737 & 0.740 \\
\hline & Sichuan & 0.570 & 0.807 & 0.678 \\
\hline & Ningxia & 0.603 & 0.683 & 0.642 \\
\hline & Guangxi & 0.513 & 0.742 & 0.617 \\
\hline & Shaanxi & 0.378 & 0.893 & 0.581 \\
\hline & Yunnan & 0.418 & 0.738 & 0.556 \\
\hline & Inner Mongolia & 0.257 & 1.000 & 0.507 \\
\hline & Gansu & 0.313 & 0.698 & 0.467 \\
\hline & Guizhou & 0.341 & 0.632 & 0.464 \\
\hline & Western region & 0.498 & 0.831 & 0.643 \\
\hline
\end{tabular}

TABLE 5: Comparative analysis of evaluation results of the SBM model and EBM model.

\begin{tabular}{ccccc}
\hline Year & $\begin{array}{c}\text { SBM model } \\
\text { Technology development } \\
\text { stage efficiency }\end{array}$ & $\begin{array}{c}\text { EBM model } \\
\text { Achievent transformation } \\
\text { stage efficiency }\end{array}$ & $\begin{array}{c}\text { Technology development stage } \\
\text { efficiency }\end{array}$ & $\begin{array}{c}\text { Achievement transformation stage } \\
\text { efficiency }\end{array}$ \\
\hline 2008 & 0.518 & 0.731 & 0.484 & 0.892 \\
2009 & 0.503 & 0.688 & 0.466 & 0.86 \\
2010 & 0.541 & 0.711 & 0.492 & 0.865 \\
2011 & 0.548 & 0.818 & 0.556 & 0.951 \\
2012 & 0.583 & 0.838 & 0.585 & 0.978 \\
2013 & 0.595 & 0.923 & 0.64 & 0.93 \\
2014 & 0.589 & 0.878 & 0.573 & 0.96 \\
2015 & 0.584 & 1.001 & 0.528 & 0.934 \\
2016 & 0.577 & 0.921 & 0.505 & 0.914 \\
2017 & 0.61 & 0.868 & 0.524 & 0.977 \\
\hline
\end{tabular}

unreasonable industrial structure. Most provinces in the central region such as Shanxi and Inner Mongolia take energy industry as the development pillar, and these traditional industries are difficult to carry out technology innovation. In addition, the talent introduction might be another explanation. Enterprises in traditional industries have less demand for high-quality talents, and most of these enterprises cannot provide a highly competitive salary, which further exacerbates the brain drain. At the same time, most enterprises in the central region are dominated by the energy and manufacturing industries, which will produce a large number of undesirable outputs in the process of industrial activities. Obviously, imitation innovation is no longer adapted to the current development stage. In order to change the situation, cities in the central region must accelerate independent innovation. 


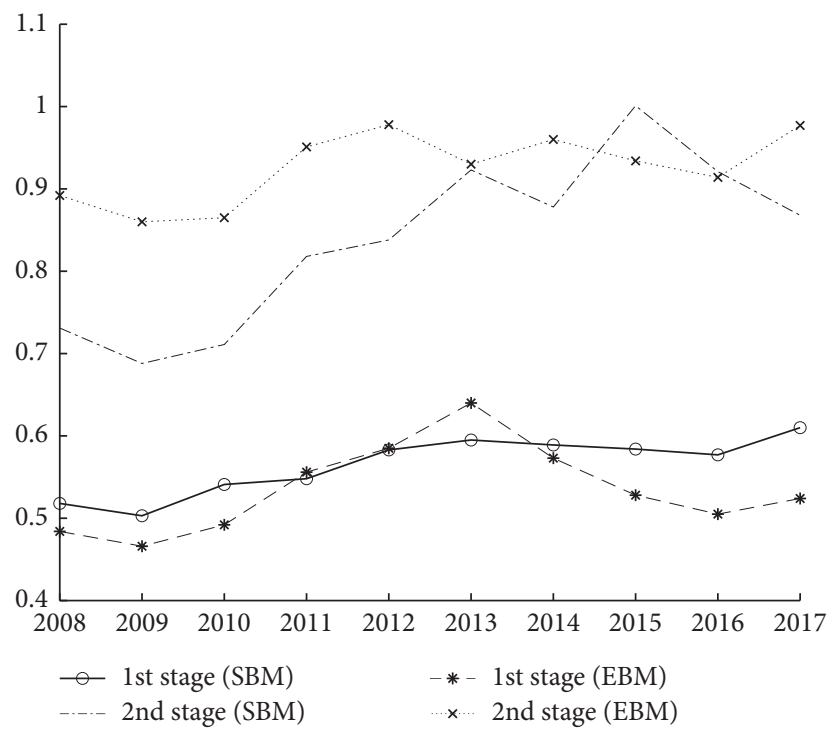

FIgURE 3: Comparative analysis of evaluation results of the SBM model and EBM model.

TABLE 6: Comparative analysis of evaluation results (SBM model/EBM model).

\begin{tabular}{|c|c|c|c|c|}
\hline \multicolumn{2}{|c|}{ DMU (province) } & The first stage efficiency & The second stage efficiency & Total efficiency \\
\hline \multirow{12}{*}{ Eastern region } & Hainan & $0.927 / 1$ & $5.550 / 1$ & $2.268 / 1$ \\
\hline & Guangdong & $2.612 / 0.922$ & $0.692 / 1.791$ & $1.345 / 1.285$ \\
\hline & Beijing & $1.649 / 0.881$ & $0.808 / 1.323$ & $1.154 / 1.080$ \\
\hline & Zhejiang & $0.687 / 0.994$ & $1.321 / 1.127$ & $0.953 / 1.059$ \\
\hline & Jiangsu & $0.848 / 0.837$ & $1.066 / 1.085$ & $0.950 / 0.953$ \\
\hline & Shanghai & $0.725 / 0.826$ & $1 / 1$ & $0.852 / 0.909$ \\
\hline & Tianjin & $0.610 / 0.677$ & $1 / 1$ & $0.781 / 0.823$ \\
\hline & Fujian & $0.437 / 0.546$ & $0.978 / 0.960$ & $0.654 / 0.724$ \\
\hline & Shandong & $0.419 / 0.491$ & $1 / 1$ & $0.647 / 0.700$ \\
\hline & Hebei & $0.335 / 0.355$ & $0.955 / 0.961$ & $0.565 / 0.584$ \\
\hline & Liaoning & $0.414 / 0.463$ & $0.742 / 0.818$ & $0.554 / 0.616$ \\
\hline & Geometric mean & $0.718 / 0.689$ & $1.106 / 1.074$ & $0.891 / 0.860$ \\
\hline \multirow{9}{*}{ Central region } & Jilin & $0.343 / 0.420$ & $1.148 / 1.027$ & $0.628 / 0.657$ \\
\hline & Henan & $0.378 / 0.407$ & $1.038 / 0.999$ & $0.626 / 0.638$ \\
\hline & Hubei & $0.471 / 0.472$ & $0.790 / 0.892$ & $0.610 / 0.649$ \\
\hline & Hunan & $0.657 / 0.525$ & $0.553 / 0.819$ & $0.603 / 0.656$ \\
\hline & Anhui & $0.852 / 0.463$ & $0.380 / 0.725$ & $0.569 / 0.579$ \\
\hline & Jiangxi & $0.328 / 0.366$ & $0.788 / 0.846$ & $0.509 / 0.557$ \\
\hline & Heilongjiang & $0.338 / 0.346$ & $0.746 / 0.843$ & $0.502 / 0.540$ \\
\hline & Shanxi & $0.327 / 0.239$ & $0.475 / 0.639$ & $0.394 / 0.391$ \\
\hline & Geometric mean & $0.433 / 0.395$ & $0.696 / 0.840$ & $0.549 / 0.576$ \\
\hline \multirow{12}{*}{ Western region } & Qinghai & $0.414 / 1.155$ & $2.118 / 1.498$ & $0.937 / 1.316$ \\
\hline & Xinjiang & $0.623 / 0.711$ & $0.963 / 0.999$ & $0.774 / 0.843$ \\
\hline & Chongqing & $0.599 / 0.742$ & $0.773 / 0.736$ & $0.680 / 0.739$ \\
\hline & Sichuan & $0.720 / 0.569$ & $0.553 / 0.807$ & $0.631 / 0.678$ \\
\hline & Ningxia & $0.539 / 0.603$ & $0.673 / 0.682$ & $0.602 / 0.641$ \\
\hline & Shaanxi & $0.459 / 0.377$ & $0.687 / 0.893$ & $0.562 / 0.580$ \\
\hline & Yunnan & $0.629 / 0.418$ & $0.471 / 0.738$ & $0.544 / 0.555$ \\
\hline & Guangxi & $0.472 / 0.512$ & $0.619 / 0.742$ & $0.540 / 0.616$ \\
\hline & Inner Mongolia & $0.237 / 0.257$ & $1.201 / 1$ & $0.534 / 0.507$ \\
\hline & Guizhou & $0.792 / 0.340$ & $0.278 / 0.631$ & $0.470 / 0.463$ \\
\hline & Gansu & $0.405 / 0.313$ & $0.465 / 0.697$ & $0.434 / 0.467$ \\
\hline & Geometric mean & $0.511 / 0.497$ & $0.695 / 0.831$ & $0.596 / 0.643$ \\
\hline
\end{tabular}

Increased investment in scientific and technological innovation can promote the efficiency of green technology investment. Due to more investments in the introduction, purchase, assimilation, and upgrading of technologies, the technology development efficiency of the western region is higher than that of the central region. However, the 
independent innovation capacity of the western region is still relatively weak; this is mainly because the investment is far less than that of the eastern and central regions. Besides, due to the weak industrial base and less undesirable outputs, the efficiency value in achievement transformation stage is slightly higher than that in the central region.

\section{Conclusions and Suggestions}

Green technology innovation is the main driving force for sustainable development of China's strategic emerging industries. In this paper, green technology innovation activities are divided into two stages based on the innovation value chain, and key undesirable outputs with negative externality to the environment are considered. On this basis, this paper constructs a two-stage evaluation system where the SBM model, the EBM model, and the network DEA model are used comprehensively and analyzes the green technology innovation efficiency for China's industrial enterprises from the perspective of time and space. The results show that the efficiency value of the second stage (achievement transformation stage) is significantly higher than that of the first stage (technology development stage); there are noticeable gaps in the efficiency of green technology innovation between different regions of China. According to the evaluation results, the following suggestions are put forward:

(1) Coordinate regional industrial development and promote the spread of green technology. To realize the interconnection and open sharing of science and technology, the government should closely focus on the demand of regional collaborative innovation and promote the regional integration of technology and relevant trading markets. Referring to the results in this study, the eastern region has better performance in green technology innovation and it can take the lead to build an open innovation highland of China and play a better role to drive the development of other regions. To form a reasonable development echelon, Beijing-Tianjin-Hebei, Changjiang delta economic development zone and the Pearl River delta should be built as the development highland of innovation transformation and upgrading in eastern China afterwards. For the central and western regions, the government should lead the way to optimize the innovation bases layout and explore the technology innovation model combined with respective characteristics.

(2) Improve the green technology innovation environment and foster the science and technology innovation industry. The government can take the policy discount and price subsidies to environmental type enterprises and products and reduce the import tariffs to environmentally friendly equipment. Give priority to develop the environmental industry, recycling industry, environmental protection industry, and green food industry to incent and guarantee the green technology innovation behavior.
(3) Improve the environmental supervision mechanism and the environmental governance level. Whether using the environment harmless technology in the production process has a significant connection with relevant industrial policies and standards. As a consequence, strengthening the research work of environmental technology standards, formulating the corresponding development strategy according to the mainstream trend of international environmental technology standards, and improving the environmental standards system are the ways of environmental supervision mechanism improvement. In addition, environmental protection departments should actively participate in enterprises' economic decision-making and timely make assessment and analysis of the environmental impact to provide some support for environmental governance.

(4) Increase the investment in green innovation and speed up the talents cultivation. In this paper, no matter SBM model or EBM model, the total efficiency of green technology innovation of China's industrial enterprises has remained at least 0.6 in recent ten years. These results indicate that China still has sufficient development potential to improve green innovation by increasing human and financial resource investment.

(5) Large industrial enterprise groups can set up green production branches in different regions and put these branches into production directly in the areas with more sales. This not only reduces transportation costs but also increases the aggregation degree of large and medium-sized enterprises, forming a scale effect. This new production model can make the production process more compact and reduce energy consumption. In addition, the popularization of largescale green production equipment is conducive to further increasing the degree of mechanization and automation of industrial production, improving the technology innovation efficiency, and reducing radioactive pollutants in the production process. With the help of international development, the advanced technology introduced from overseas can improve the efficiency of green technology innovation and better meet the requirements of ecological environment protection and sustainable economic development.

\section{Discussion}

The thesis addresses the shortcomings of the existing literature on green innovation efficiency by comparing SBM with EBM, and the research proposal of the thesis can fully demonstrate the details of the components of green innovation efficiency. The thesis improved accuracy of the identification of technological innovation efficiency. The model can be applied to green technology innovation companies to enable them to scientifically develop their research plans by analyzing their innovation efficiency. The widespread 
application of the model can generate savings in research costs and increase research output. In the future, it is proposed to include multisource heterogeneous data as well as nondesired output indicators to increase the accuracy of the evaluation of the efficiency of green technology innovation.

\section{Data Availability}

The data used to support the findings of this study are available from the corresponding author upon request.

\section{Conflicts of Interest}

The authors declare that they have no conflicts of interest.

\section{Acknowledgments}

The authors appreciate the funding support from the Soft Science Project of the State Intellectual Property Office (SS20B-17), Heilongjiang Province Philosophy and Social Science Planning Project (20GYB041), Natural Science Foundation of Heilongjiang Province (G2017001), and the Research projects of East University of Heilongjiang (HDFKY200216).

\section{References}

[1] R. Kemp, K. Smith, and G. Becher, "How should we study the relationship between environmental regulation and innovation?" Innovation-Oriented Environmental Regulation, Springer, Berlin, Germany, pp. 43-66, 2000.

[2] L. Luo and S. Liang, "Green technology innovation efficiency and factor decomposition of China's industrial enterprises," China Population, Resources and Environment, vol. 26, no. 9, pp. 149-157, 2016, in Chinese.

[3] L. Qian, W. Wang, and R. Xiao, "Research on the regional disparities of China's industrial enterprises green innovation efficiency from the perspective of shared inputs," China Population, Resources and Environment, vol. 28, no. 5, pp. 27-39, 2018, in Chinese.

[4] M. Szajt, "Aktywność patentowa państw OECD w ujęciu regionalnym - konwergencja czy utrzymanie status quo," Studies of the Industrial Geography Commission of the Polish Geographical Society, vol. 31, no. 4, pp. 40-51, 2017.

[5] J. Bai, K. Jiang, and J. Li, "Convergence analysis of regional innovation efficiency in China," Finance and Trade Economy, vol. 28, no. 9, pp. 119-123, 2008, in Chinese.

[6] X. Li and H. Long, "Research focus, frontier and knowledge base of green technology in China: metrological research based on mapping knowledge domains," Polish Journal of Environmental Studies, vol. 29, no. 5, pp. 3003-3011, 2020.

[7] X. Pan and F. Liu, "Research on industrial enterprise's innovation efficiency in China based on regional comparison," Management Review, vol. 22, no. 2, pp. 59-64, 2010, in Chinese.

[8] X. Li and J. Zhu, "Innovation efficiency and convergence research on China's provincial industrial enterprises," Journal of Applied Statistics and Management, vol. 32, no. 6, pp. 1090-1099, 2013, in Chinese.

[9] K. Zhang, W. Jiang, Y. Xu, Y. Hou, S. Zhang, and W. Liu, "Assessing the corporate green technology progress and environmental governance performance based on the panel data on industrial enterprises above designated size in Anhui Province, China," Environmental Science and Pollution Research, vol. 28, no. 1, pp. 1151-1169, 2021.
[10] J.-L. Furman, M.-E. Porter, and S. Scott, "The determinants of national innovative capacity," Research Policy, vol. 31, no. 6, pp. 899-933, 2002.

[11] M. T. Hansen and J. Birkinshaw, "The innovation value chain," Harvard Business Review, vol. 85, no. 6, pp. 121-142, 2007.

[12] C. Liu, X. Gao, W. Ma, and X. Chen, "Research on regional differences and influencing factors of green technology innovation efficiency of China's high-tech industry," Journal of Computational and Applied Mathematics, vol. 369, 2020.

[13] Z. Fang, B. Hua, and B. Yuriy, "Evaluation research of green innovation efficiency in China's heavy polluting industries," Sustainability, vol. 12, no. 1, p. 146, 2020.

[14] K. Tang, Y. Qiu, and D. Zhou, "Does command-and-control regulation promote green innovation performance? Evidence from China's industrial enterprises," Science of the Total Environment, vol. 712, p. 136362, 2020.

[15] R. Xiao, Z. Wang, and L. Qian, "Research on the industrial enterprise's innovation efficiency in China considering environmental factors," Management Review, vol. 26, no. 6, pp. 56-66, 2014, in Chinese.

[16] M. Bai, Y. Zhang, Y. Fu et al., "Research on the efficiency of green technology innovation in iron and steel enterprises from the perspective of innovation value chain," Journal of Anhui University of Technology (Social Sciences), vol. 36, no. 5, pp. 13-16, 2019, in Chinese.

[17] J. Xu, M. Wang, and J. Guan, "Research on mechanism of carbon emission from energy consumption and green innovation efficiency in dynamic endogenous perspective based on Chinese equipment manufacturing industries," Management Review, vol. 31, no. 9, pp. 81-93, 2019, in Chinese.

[18] F. Fan, H. Lian, X. Liu, and X. Wang, "Can environmental regulation promote urban green innovation efficiency? an empirical study based on Chinese cities," Journal of Cleaner Production, vol. 287, p. 125060, 2021.

[19] S. Wang, M. Jia, Y. Zhou, and F. Fan, "Impacts of changing urban form on ecological efficiency in China: a comparison between urban agglomerations and administrative areas," Journal of Environmental Planning and Management, vol. 63, no. 10, pp. 1834-1856, 2020. 